\title{
Colorectal Peutz-Jeghers Polyp
}

National Cancer Institute

\section{Source}

National Cancer Institute. Colorectal Peutz-Jeghers Polyp. NCI Thesaurus. Code C5519.

A non-neoplastic hamartomatous polyp that arises from the colon and rectum. It is

characterized by the presence of smooth muscle branching bands, and cystic mucosal changes. 